Pacific Journal of Mathematic

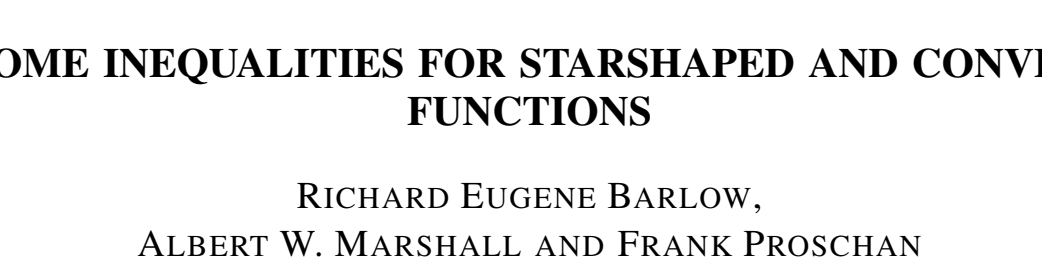




\title{
SOME INEQUALITIES FOR STARSHAPED AND CONVEX FUNCTIONS
}

\author{
Richard E. Barlow, Albert W. Marshall \\ and Frank Proschan
}

\begin{abstract}
Necessary and sufficient conditions are obtained on a function $G$ of bounded variation such that $\phi\left(\int x(t) d G(t)\right) \leqq$ $\int \phi(x(t)) d G(t)$ for all increasing $x$ for which $x\left(t_{0}\right)=0$ for some specified $t_{0}$, and all convex $\phi$ for which $\phi(0)=0$; the conditions are otherwise independent of $\phi$ and $x$. Similar results are obtained when the inequality is reversed. Necessary and sufficient conditions for both directions of inequality are also obtained when $\phi$ is starshaped and $\phi(0)=0$.

The relationship to previous results is sketched. Applications to statistical tolerance limits are indicated.
\end{abstract}

Several inequalities are known that give necessary and sufficient conditions for a signed measure $\mu$ to satisfy

$$
\int \phi(x) d \mu(x) \geqq 0
$$

for all functions $\phi$ in a given convex cone. For example, such results were obtained by Hardy, Littlewood and Pólya [7] for the cone of convex functions, and by Karlin and Novikoff [9], Ziegler [17] and Karlin and Studden [10] for cones of generalized convex functions.

By changing variables in such a result, it is easy to obtain conditions on $\mu$ in order that

$$
\int \phi(x(t)) d \mu(t) \geqq 0
$$

for all $\phi$ in the given convex cone, where $x$ is an increasing function. Generally speaking the conditions so obtained depend upon the function $x$. In some applications, $x$ is replaced by a random function (see Barlow and Proschan [1]). Inequalities are thus required which will hold for essentially all possible realizations of the random function, so that those obtained via a change of variables, like (1.2), are not useful.

In this paper, we consider only measures $\mu$ which are the difference between a measure $\nu$ and the measure which has unit mass concentrated at the point $\int x(t) d \nu(t)$. Consequently, all the inequalities that we obtain have either the form

$$
\phi\left(\int x(t) d \nu(t)\right) \leqq \int \phi(x(t)) d \nu(t)
$$


or

$$
\phi\left(\int x(t) d \nu(t)\right) \geqq \int \phi(x(t)) d \nu(t) .
$$

For the cone of the convex functions $\phi$ satisfying $\dot{\phi}(0)=0 \quad(\S 3)$ and the cone of starshaped functions $(\S 4)$, conditions on $\nu$ are given for (1.3) or (1.4) which are independent of the function $x$.

For discrete measures and convex functions $\phi$, sufficient conditions independent of the function $x$ have been obtained by various authors (see $\S 5$ ). For more general measures and convex $\phi$, sufficient conditions have been obtained by Brunk [5]. The relation between our work and his is discussed in $\S 3$. Related results in higher dimensions have also been obtained by Brunk [6].

In all of these cases, the direction of the inequality is as in (1.3), and of course this is also the direction of Jensen's inequality. Thus, results of the form (1.4) are more novel.

Observe that inequalities of the form (1.2) can be viewed as having the form of (1.1) where the original cone of functions is extended by increasing transformations of the variable. We have not found it convenient to adopt this point of view; instead, the results are obtained via inequalities of the form (1.1) for the original cones of functions. These preliminary inequalities are given in $\S 2$.

Throughout this paper, we use "increasing" in place of "nondecreasing" and "decreasing" in place of "nonincreasing". We consider functions defined on intervals $[a, b]$; although the endpoints $a$ and $b$ need not be finite, it should always be understood that they are to be included in an interval only if they are finite.

2. Preliminary inequalities. One of the earliest inequalities of the form (1.1) is the result of Hardy, Littlewood and Pólya [7] for convex functions. They observed that a convex function can be approximated by positive combinations of functions of the form

$$
\phi(x)=x, \quad \phi(x)=-x, \quad \phi(x)=1, \quad \phi(x)=-1
$$

and

$$
\phi(x)=\left\{\begin{array}{c}
x-u, x>u \\
0, \quad x \leqq u,
\end{array}-\infty<u<\infty .\right.
$$

Their conclusion was that (1.1) holds for all convex $\phi$ if and only if it holds for these special convex $\phi$. The idea of their proof can be used to obtain several related inequalities that we shall require. These inequalities all characterize the signed measures $\mu$ of bounded variation that satisfy 


$$
\int_{[a, b]} \phi(x) d \mu(x) \geqq 0
$$

for all functions $\phi$ of a given class $\mathscr{C},-\infty \leqq a<b \leqq \infty$. The results are obtained by finding a subclass $\mathscr{D} \subset \mathscr{C}$ with the property that for all $\phi \in \mathscr{C}$, there exists a sequence $\left\{\phi_{i}\right\}$ of positive combinations of elements of $\mathscr{D}$ such that $\lim _{i} \phi_{i}(x)=\phi(x)$. Furthermore the sequence has the property that $\phi_{i}(x)$ is increasing in $i$ if $\phi(x) \geqq 0$ and $\phi_{i}(x)$ is decreasing in $i$ if $\phi(x) \leqq 0$. From the Lebesgue monotone convergence theorem, we have that $\int_{[a, b]} \phi(x) d \mu(x) \geqq 0$ for all $\phi \in \mathscr{D}$ if and only if the inequality holds for all $\phi \in \mathscr{C}$. The following theorems can be easily proved in this way; in each case, the class $\mathscr{C}$ is stated in the hypotheses of the theorem and the class $\mathscr{D}$ can be reconstructed from the conditions given.

THEOREM 2.1. $\int_{[a, b]} \phi(x) d \mu(x) \geqq 0$ for all $\phi$ convex on $[a, b]$ such that $\phi(c)=0, a \leqq c \leqq b$, with $c$ finite, if and only if

$$
\begin{aligned}
& \int_{[u, b]}(x-u) d \mu(x) \geqq 0 \quad \text { for all } u \in[c, b), \\
& \int_{[a, u]}(u-x) d \mu(x) \geqq 0 \text { for all } u \in(a, c],
\end{aligned}
$$

and

$$
\int_{[a, b]}(x-c) d \mu(x)=0 \text {. }
$$

If $\phi$ satisfies the conditions of Theorem 2.1 and $\int_{[a, b]} \phi(x) d \mu(x)=0$ for all measures $\mu$ satisfying (2.1), (2.2) and (2.3), then $\phi(x)=\alpha(x-c)$. In fact, by considering measures $\mu$ of the form $\mu\left\{x_{1}\right\}=\theta, \mu\left\{x_{2}\right\}=1-\theta$, $\mu\left\{\theta x_{1}+(1-\theta) x_{2}\right\}=-1\left(a \leqq x_{1} \leqq c \leqq x_{2} \leqq b, 0<\theta<1\right)$, we conclude from $\int_{[a, b]} \phi(x) d \mu(x)=0$ that $\phi$ is linear because $\phi\left(\theta x_{1}+(1-\theta) x_{2}\right)=$ $\theta \phi\left(x_{1}\right)+(1-\theta) \phi\left(x_{2}\right)$.

We remark that without the condition $\phi(c)=0$, the conditions (2.1) - (2.3) must be augmented by the requirement that $\int_{[a, b]} d \mu=0$. This is essentially the result of Hardy, Littlewood and Pólya [7]. See also Karamata [8], Levin and Stečkin [12], Brunk [5], and Karlin and Novikoff [9].

THEOREM 2.2. $\int_{[a, b]} \phi(x) d \mu(x) \geqq 0$ for all $\phi$ convex on $[a, b]$ such that $\phi(c)=0, a \leqq c \leqq b$ with $c$ finite, and $\phi(x) \geqq 0, a \leqq x \leqq b$, if and only if (2.1) and (2.2) hold. 
Equality $\int_{[a, b]} \phi(x) d \mu(x)=0$ in Theorem 2.2 is obtained for all measures $\mu$ satisfying (2.1) and (2.2) if and only if $\phi(x)=0$ when $a<c<b, \phi(x)=\alpha(x-c)$ when $c=a$ or $c=b$. This can be obtained in the same way as the case of equality in Theorem 2.1.

Without the condition $\phi(c)=0,(2.1)$ and (2.2) are no longer sufficient, but in this case, the appropriate conditions can be found as a special case of results due to Ziegler [17]. See also Karlin and Studden [10].

The remaining theorems of this section are concerned with starshaped functions. Perhaps the most natural domain for these functions is $[0, \infty)$, where they are considered by Bruckner and Ostrow [4]. Our original interest in these functions was also on this domain, where they arise in describing certain classes of probability distributions of importance in reliability theory and elsewhere (see Barlow and Proschan [1]). However, we consider more general domains here, and extend the definition in two ways.

DEFinition 2.3. A real valued function $\phi$ on the interval $I$ is said to be starshaped if $\phi(\alpha x) \leqq \alpha \phi(x)$ whenever $x \in I, \alpha x \in I$ and $0 \leqq \alpha \leqq 1$.

DEFinition 2.4. A real valued function on the interval $I$ is said to be a supported starshaped function if it is starshaped, and if, whenever 0 is an interior point of $I$, there exists a linear function $l$ on $I$ such that $l(0)=0$ and $l(x) \leqq \phi(x)$ for all $x \in I$.

Unless 0 is an interior point of $I$, there is no distinction between starshaped and supported starshaped functions. If 0 is an interior point of $I$, then $\phi$ is starshaped on $I$ if and only if

(i ) $\phi(x) / x$ is increasing in $x<0, x \in I$,

(ii) $\phi(x) / x$ is increasing in $x>0, x \in I$,

(iii) $\phi(0) \leqq 0$.

On the other hand, if 0 is an interior point of $I, \phi$ is a supported starshaped function on $I$ if and only if

(iv) $x_{1}<x_{2}$ and $x_{1} \neq 0 \neq x_{2}$ implies $\phi\left(x_{1}\right) / x_{1} \leqq \phi\left(x_{2}\right) / x_{2}$,

(v) $\phi(0)=0$.

When the interval $I$ is of the form $[0, b]$, then a starshaped function $\phi$ is a generalized convex function in the sense defined by Karlin and Novikoff [9] and Ziegler [17]; in the notation of Karlin and Studden [10], $n=0$ and $u_{0}(x)=x$. In this case, theorems similar to those below are obtainable as special cases of their results.

\footnotetext{
THEOREM 2.5. $\int_{[a, b]} \phi(x) d \mu(x) \geqq 0$ for all starshaped $\phi$ on $[a, b]$, $a \leqq 0 \leqq b$, such that $\phi(0)=0$ if and only if
} 


$$
\begin{aligned}
& \int_{[a, 0]} x d \mu(x)=\int_{[0, b]} x d \mu(x)=0, \\
& \int_{[a, u]} x d \mu(x) \leqq 0 \quad \text { for all } u, \quad a \leqq u<0, \\
& \int_{[u, b]} x d \mu(x) \geqq 0 \text { for all } u, \quad 0<u \leqq b .
\end{aligned}
$$

THEOREM 2.6. $\int_{[a, b]} \phi(x) d \mu(x) \geqq 0$ for all supported starshaped $\phi$ on $[a, b], a \leqq 0 \leqq b$, such that $\phi(0)=0$ if and only if (2.5), (2.6), and

$$
\int_{[a, b]} x d \mu(x)=0 \text {. }
$$

3. Inequalities for convex functions. In the following, $G$ denotes a function of bounded variation on $[a, b],-\infty \leqq a \leqq 0 \leqq b \leqq \infty$ (the endpoints of the interval are excluded when not finite). We assume that $G(u)=\int_{[a, u]} d G(x)$, and use the notation $\bar{G}(u)=\int_{(u, b]} d G(x)$. In addition, we assume without further mention that $\int_{[a, b]} x(t) d G(t)<\infty$. Occasionally, we find it convenient to use the letter $G$ to denote the measure determined by $G$ : i.e., we write $G\{A\}=\int_{A} d G(x)$.

Theorem 3.1. Let $t_{0} \in[a, b]$ be fixed.

$$
\phi\left(\int_{[a, b]} x(t) d G(t)\right) \leqq \int_{[a, b]} \phi(x(t)) d G(t)
$$

for all convex functions $\phi$ such that $\phi(0)=0$ and all increasing functions $x$ such that $x\left(t_{0}\right)=0$ if and only if

$$
0 \leqq G(t) \leqq 1, a \leqq t<t_{0} \text { and } 0 \leqq \bar{G}(t) \leqq 1, t_{0} \leqq t<b
$$

REMARK. In this and the following theorems, $\phi$ need not be convex (or even defined) over all of the interval $(-\infty, \infty)$. But $\phi$ must be convex on an interval containing the point $\int_{[a, b]} x(t) d G(t)$ and the range of $x(t)$ for $t$ in the support of $G$.

Proof. Suppose first that (3.2) holds. Let

$$
G^{*}(z)=G\{t: a \leqq t \leqq b \text { and } x(t) \leqq z\},
$$

and let $H^{*}$ be the probability distribution degenerate at $\mu=\int_{-\infty}^{\infty} x d G^{*}(z)$. Since $G^{*}$ has no mass outside the interval $[x(a), x(b)],(3.1)$ can be rewritten as 


$$
\int_{-\infty}^{\infty} \phi(z) d H^{*}(z) \leqq \int_{-\infty}^{\infty} \phi(z) d G^{*}(z)
$$

Observe that (3.2) can be rewritten as

$$
0 \leqq G^{*}(z) \leqq 1, z \leqq 0 \text { and } 0 \leqq \bar{G}^{*}(z) \leqq 1, z \geqq 0 \text {. }
$$

By definition of $H^{*}$, we have that $\int_{-\infty}^{\infty} z d G^{*}(z)=\int_{-\infty}^{\infty} z d H^{*}(z)$. Thus, by Theorem 2.1, we need only check that

$$
\int_{u}^{\infty} \bar{G}^{*}(z) d z \geqq \int_{u}^{\infty} \bar{H}^{*}(z) d z, u \geqq 0
$$

and

$$
\int_{-\infty}^{u} G^{*}(z) d z \geqq \int_{-\infty}^{u} H^{*}(z) d z, u \leqq 0
$$

Case 1. $u \geqq 0$. If

$$
u \leqq \mu, \int_{u}^{\infty} \bar{H}^{*}(z) d z=\mu-u=\int_{0}^{\infty} \bar{G}^{*}(z) d z-\int_{-\infty}^{0} G^{*}(z) d z-u
$$

so that $\int_{u}^{\infty} \bar{G}^{*}(z) d z \geqq \int_{u}^{\infty} \bar{H}^{*}(z) d z$ is equivalent to

$$
\int_{-\infty}^{0} G^{*}(z) d z+u \geqq \int_{0}^{u} \bar{G}^{*}(z) d z
$$

But this follows from $G^{*}(z) \geqq 0, z \leqq 0$, and $\bar{G}^{*}(z) \leqq 1, z \geqq 0$.

If $u \geqq \mu, \int_{u}^{\infty} \bar{H}^{*}(z) d z=0$ so that $\int_{u}^{\infty} \bar{G}^{*}(z) d z \geqq \int_{u}^{\infty} \bar{H}^{*}(z) d z$ is equivalent to $\int_{u}^{\infty} \bar{G}^{*}(z) d z \geqq 0$. This follows from $\bar{G}^{*}(z) \geqq 0, z \geqq 0$.

Case 2. $u \leqq 0$. If $u \leqq \mu$, then $\int_{-\infty}^{u} G^{*}(z) d z \geqq \int_{-\infty}^{u} H^{*}(z) d z=0$ since $G^{*}(z) \geqq 0, z \leqq 0$, while $H^{*}(z)=0, z \leqq \mu$.

If $u>\mu, \int_{-\infty}^{u} H^{*}(z) d z=u-\mu=u-\int_{0}^{\infty} \bar{G}^{*}(z) d z+\int_{-\infty}^{0} G^{*}(z) d z$ and so $\int_{-\infty}^{u} G^{*}(z) d z \geqq \int_{-\infty}^{u} H^{*}(z) d z$ is equivalent to

$$
\int_{0}^{\infty} \bar{G}^{*}(z) d z-u \geqq \int_{u}^{0} G^{*}(z) d z .
$$

But this is a consequence of $\overline{G^{*}}(z) \geqq 0, z \geqq 0$, and $G^{*}(z) \leqq 1, z \leqq 0$.

It remains to show that (3.2) is necessary. Choose $t_{1} \geqq t_{0}$. Let

$$
x(t)= \begin{cases}0, & t \leqq t_{1} \\ 1, & t>t_{1}\end{cases}
$$


and let $\phi(z)=z^{2}$. Then (3.1) becomes

$$
\int_{\left(t_{1}, b\right]} d G(t) \geqq\left(\int_{\left(t_{1}, b\right]} d G(t)\right)^{2},
$$

i.e., $\bar{G}\left(t_{1}\right) \geqq\left[\bar{G}\left(t_{1}\right)\right]^{2}$. This implies $0 \leqq \bar{G}\left(t_{1}\right) \leqq 1$.

Next, choose $t_{2}<0$.

Let

$$
x(t)=\left\{\begin{aligned}
-1, & t \leqq t_{2} \\
0, & t>t_{2},
\end{aligned}\right.
$$

and again take $\phi(z)=z^{2}$. Then (3.1) becomes $G\left(t_{2}\right) \geqq\left[G\left(t_{2}\right)\right]^{2}$, hence $0 \leqq G\left(t_{2}\right) \leqq 1$.

If $\phi$ is convex, then $\psi(x)=\phi(x)-\dot{\phi}(0)$ is convex and satisfies $\psi(0)=0$, so that Theorem 3.1 can be restated without the hypothesis $\dot{\phi}(0)=0$ as follows:

Theorem 3.1a. Fix $t_{0} \in[a, b]$.

$$
\dot{\phi}\left(\int_{[a, b]} x(t) d G(t)\right)-\dot{\phi}(0) \leqq \int_{[a, b]}[\dot{\phi}(x(t))-\dot{\phi}(0)] d G(t)
$$

for all convex functions $\phi$ and increasing functions $x$ such that $x\left(t_{0}\right)=$ 0 if and only if (3.2).

If the hypotheses of Theorem 3.1a are augmented by the condition $\phi(0) \leqq \phi(0) G(b)$, then we can replace (3.3) with (3.1). The result so obtained is a modification of Theorem 3.1 that admits a widened class of functions $\phi$.

We remark that if $G$ is a probability distribution on $[a, b]$, then (3.2) is satisfied and (3.3) reduces to (3.1). Thus we obtain the special case of Jensen's inequality. The next theorem gives conditions for the reverse inequality, and here the results are somewhat more novel.

THEOREM 3.2. Fix $t_{0} \in[a, b]$.

$$
\phi\left(\int_{[a, b]} x(t) d G(t)\right) \geqq \int_{[a, b]} \phi(x(t)) d G(t)
$$

for all convex functions $\phi$ such that $\phi(0)=0$ and all increasing functions $x$ such that $x\left(t_{0}\right)=0$ if and only if either

there exists $s \leqq t_{0}$ such that $G(t) \leqq 0, t<s, G(t) \geqq 1$, $s \leqq t<t_{0}$ and $\bar{G}(t) \leqq 0, t \geqq t_{0}$, 


$$
\begin{aligned}
& \text { there exists } s \geqq t_{0} \text { such that } G(t) \leqq 0, t<t_{0}, \bar{G}(t) \geqq 1 \text {, } \\
& t_{0} \leqq t<s, \text { and } \bar{G}(t) \leqq 0, t \geqq s .
\end{aligned}
$$

Proof. Let $H^{*}(z)=G\{t: a \leqq t \leqq b$ and $x(t) \leqq z\}$, and let $G^{*}$ be the probability distribution degenerate at $\mu=\int_{-\infty}^{\infty} z d H^{*}(z)$. Then (3.4) can be rewritten as

$$
\int_{-\infty}^{\infty} \phi(z) d G^{*}(z) \geqq \int_{-\infty}^{\infty} \phi(z) d H^{*}(z)
$$

Suppose that (3.6) holds. We may rewrite it in the following way:

$$
\begin{aligned}
& \text { There exists } y \geqq 0 \text { such that } H^{*}(z) \leqq 0, z<0, \bar{H}^{*}(z) \geqq 1 \text {, } \\
& 0 \leqq z<y \text {, and } \bar{H}^{*}(z) \leqq 0, z \geqq y
\end{aligned}
$$

Since $\int_{-\infty}^{\infty} z d G^{*}(z)=\int_{-\infty}^{\infty} z d H^{*}(z)$, we can apply Theorem 2.1 by checking that

$$
\int_{u}^{\infty} \bar{G}^{*}(z) d z \geqq \int_{u}^{\infty} \bar{H}^{*}(z) d z, u H^{*}(z) \geqq 0, \text { and } \int_{-\infty}^{u} G^{*}(z) d z \geqq \int_{-\infty}^{u} H^{*}(z) d z, u \leqq 0
$$

Case 1a. $0 \leqq u \leqq \mu$. The condition $\int_{u}^{\infty} \bar{G}^{*}(z) d z \geqq \int_{u}^{\infty} \bar{H}^{*}(z) d z$ becomes $\mu-u \geqq \int_{u}^{\infty} \bar{H}^{*}(z) d z$, i.e.,

$$
\int_{0}^{\infty} \bar{H}^{*}(z) d z-\int_{-\infty}^{0} H^{*}(z) d z-u \geqq \int_{u}^{\infty} \bar{H}^{*}(z) d z
$$

or

$$
\int_{0}^{u} \bar{H}^{*}(z) d z \geqq u+\int_{-\infty}^{0} H^{*}(z) d z
$$

If $u<y$, this follows from $\bar{H}^{*}(z) \geqq 1,0 \leqq z \leqq u$ and $H^{*}(z) \leqq 0$, $z<0$.

If $u>y$, we employ the condition $u \leqq \mu$ together with $\int_{u}^{\infty} \bar{H}^{*}(z) d z \leqq$ 0 to conclude $\mu-u \geqq \int_{u}^{\infty} \bar{H}^{*}(z) d z$.

Case 1b. $u \geqq 0$ and $u \geqq \mu$. Then $\int_{u}^{\infty} \bar{G}^{*}(z) d z \geqq \int_{u}^{\infty} \bar{H}^{*}(z) d z$ is just $0 \geqq \int_{u}^{\infty} \bar{H}^{*}(z) d z$. If $u \geqq y$, this is a trivial consequence of $\bar{H}^{*}(z) \leqq 0$, $z \geqq y$. If $u \leqq y$, we observe that $u \geqq \mu$ is equivalent to

$$
u \geqq-\int_{-\infty}^{0} H^{*}(z) d z+\int_{0}^{u} \bar{H}^{*}(z) d z+\int_{u}^{\infty} \bar{H}^{*}(z) d z .
$$

Since $-\int_{-\infty}^{0} H^{*}(z) d z \geqq 0$ and $\int_{0}^{u} \bar{H}^{*}(z) d z \geqq u$, we conclude from this that $0 \geqq \int_{u}^{\infty} \bar{H}^{*}(z) d z$. 
Case 2a. $\mu \leqq u \leqq 0$. The condition $\int_{-\infty}^{u} G^{*}(z) d z \geqq \int_{-\infty}^{u} H^{*}(z) d z$ becomes $u-\mu \geqq \int_{-\infty}^{u} H^{*}(z) d z$. But $u-\mu \geqq 0 \geqq \int_{-\infty}^{u} H^{*}(z) d \bar{d}$.

Case $2 \mathrm{~b} . \quad u<\mu$ and $u \leqq 0$. The condition

$$
\int_{-\infty}^{u} G^{*}(z) d z \geqq \int_{-\infty}^{u} H^{*}(z) d z \quad \text { becomes } \quad 0 \geqq \int_{-\infty}^{u} H^{*}(z) d z
$$

which follows from $H^{*}(z) \leqq 0, z \leqq 0$.

Now suppose that (3.5) holds. In this case it is possible to prove (3.4) in a manner analogous to the proof just given under the supposition that (3.6) holds. Alternatively, we can use the result that (3.6) implies (3.4): Let $G^{\dagger}(x)=\bar{G}(-x), x^{\dagger}(t)=-x(-t), \phi^{\dagger}(z)=\phi(-z)$, $a^{\dagger}=-b, b^{\dagger}=-a$, and $t_{0}^{\dagger}=-t_{0}$. Then (3.6) with $G^{\dagger}$ in place of $G$ and $t_{0}^{\dagger}$ in place of $t_{0}$ is equivalent to (3.5) so it implies (3.4) with $G, x, \phi, a$ and $b$ replaced by $G^{\dagger}, x^{\dagger}, \phi^{\dagger}, a^{\dagger}$ and $b^{\dagger}$ respectively. However, (3.4) with this replacement is equivalent to (3.4) without this replacement.

Next, suppose that (3.4) holds. Choose $t_{1}<t_{0}$, let $x(t)=-1$, $t \leqq t_{1}, x(t)=0, t>t_{1}$, and let $\phi(z)=z^{2}$. Then (3.4) becomes

$$
\int_{\left[a, t_{1}\right]} d G(t) \leqq\left[\int_{\left[a, t_{1}\right]}(-1) d G(t)\right]^{2}=\left[\int_{\left[a, t_{1}\right]} d G(t)\right]^{2},
$$

i.e., $G\left(t_{1}\right) \leqq\left[G\left(t_{1}\right)\right]^{2}$. Hence $G\left(t_{1}\right) \leqq 0$ or $G\left(t_{1}\right) \geqq 1, t_{1}<t_{0}$. Similarly, by choosing $t_{1} \geqq t_{0}, x(t)=0, t \leqq t_{1}, x(t)=1, t>t_{1}$, and $\phi(z)=z^{2}$, we conclude that $\bar{G}\left(t_{1}\right) \leqq 0$ or $\bar{G}\left(t_{1}\right) \geqq 1, t_{1} \geqq t_{0}$.

Now let $t_{0} \leqq t_{1}<t_{2}<b$ and suppose that $\bar{G}\left(t_{1}\right) \leqq 0$. Let

$$
x(t)=\left\{\begin{array}{l}
0, \quad t \leqq t_{1} \\
1, \quad t_{1}<t \leqq t_{2} \\
1+\varepsilon, t_{2}<t \leqq b
\end{array}\right.
$$

Then $\int_{[a, b]} x(t) d G(t)=\bar{G}\left(t_{1}\right)-\bar{G}\left(t_{2}\right)+(1+\varepsilon) \bar{G}\left(t_{2}\right)=\bar{G}\left(t_{1}\right)+\varepsilon \bar{G}\left(t_{2}\right)$. Since $\bar{G}\left(t_{1}\right) \leqq 0$, we can choose $\varepsilon$ sufficiently small that $\bar{G}\left(t_{1}\right)+\varepsilon \bar{G}\left(t_{2}\right)<1$. Let $\phi(z)=z-1$ if $z \geqq 1$ and $\phi(z)=0$ for $z<1$. Then (3.4) becomes $\int_{\left[t_{2}, b\right]} \varepsilon d G(t) \leqq 0$, i.e., $\bar{G}\left(t_{2}\right) \leqq 0$. Similarly, if $a \leqq t_{1}<t_{2}<t_{0}$ and we let

$$
x(t)=\left\{\begin{array}{cc}
-(1+\varepsilon), & a<t \leqq t_{1} \\
-1, & t_{1}<t \leqq t_{2} \\
0, & t>t_{2},
\end{array} \quad \phi(z)=\left\{\begin{array}{cr}
-1-z, z \leqq-1 \\
0, \quad z>-1
\end{array}\right.\right.
$$

then we can conclude that $G\left(t_{2}\right) \leqq 0$ implies $G\left(t_{1}\right) \leqq 0$.

Finally, suppose that $a<t_{1}<t_{0} \leqq t_{2}<b$, and $G\left(t_{1}\right) \geqq 1, \bar{G}\left(t_{2}\right) \geqq 1$. Choose $\delta$ so small that $t_{1}<t_{0}-\delta<t_{0}$, and let $x(t)=-1 /\left\{G\left(t_{0}-\delta\right)\right\}$, 
$t \leqq t_{0}-\delta, x(t)=0, t_{0}-\delta<t \leqq t_{0}$, and $x(t)=1 /\left\{\bar{G}\left(t_{0}\right)\right\}, t>t_{0} . \quad$ Then

$$
\int_{[a, b]} x(t) d G(t)=\int_{\left[a, t_{0}-\hat{o}\right]} \frac{d G(t)}{-G\left(t_{0}-\delta\right)}+\int_{\left.t_{0}, b\right]} \frac{d G(t)}{\bar{G}\left(t_{0}\right)}=-1+1=0 .
$$

Inequality (3.4) becomes $\int_{[a, b]} \phi(x(t)) d G(t) \leqq 0$. With $\phi(z)=|z|$, we obtain

$$
\int_{\left[a, t_{0}-\tilde{\delta}\right]} \frac{d G(t)}{G\left(t_{0}\right)}+\int_{\left(t_{0}, b\right]} \frac{d G(t)}{\bar{G}\left(t_{0}\right)}=2 \leqq 0, \quad \text { a contradiction } .
$$

It follows that either (3.5) or (3.6) must be satisfied.

In the same manner as for Theorem 3.1 , it is possible to restate Theorem 3.2 without the hypothesis $\phi(0)=0$ as follows:

THEOREM 3.2a.

$$
\phi\left(\int_{[a, b]} x(t) d G(t)\right)-\phi(0) \geqq \int_{[a, b]}[\phi(x(t))-\phi(0)] d G(t)
$$

for all convex functions $\dot{\phi}$ and all increasing functions $x$ such that $x\left(t_{0}\right)=0, a \leqq t_{0} \leqq b$, if and only if either (3.5) or (3.6).

Both Theorems 3.1 and 3.2 were obtained via Theorem 2.1. It follows from the conditions for equality there that equality holds in (3.1) (in 3.4) for all $x(t)$ such that $x\left(t_{0}\right)=0$ and all $G$ satisfying (3.2) (satisfying (3.5) or (3.6)) if and only if $\phi(x)=\alpha x$. In fact the same can be said if equality holds for $x(t)=t-t_{0}$ and all $G$ satisfying the appropriate conditions. On the other hand, for certain specific $x(t)$, there may be other cases of equality.

We state several immediate but particularly interesting consequences of Theorems 3.1 and 3.2.

The condition that $\phi(0)=0$ may be of special interest for functions $\phi$ on $[0, b]$, particularly when $t_{0}=0$. In this case, we obtain the following two special cases.

Corollary 3.3.

$$
\phi\left(\int_{[0, b]} x(t) d G(t)\right) \leqq \int_{[0, b]} \phi(x(t)) d G(t)
$$

for all convex functions $\phi$ such that $\dot{\phi}(0)=0$ and all increasing functions $x$ such that $x(0)=0$ if and only if $0 \leqq \bar{G}(t) \leqq 1,0 \leqq t<b$.

COROLlary 3.4 .

$$
\phi\left(\int_{[0, b]} x(t) d G(t)\right) \geqq \int_{[0, b]} \phi(x(t)) d G(t)
$$


for all convex functions $\phi$ such that $\phi(0)=0$ and all increasing functions $x$ such that $x(0)=0$ if and only if there exists $s, 0<s<b$, such that $\bar{G}(t) \geqq 1,0 \leqq t<s$ and $\bar{G}(t) \leqq 0, s \leqq t \leqq b$.

In Theorems 3.1 and 3.2 it is assumed that a point $t_{0}$ is known such that $x\left(t_{0}\right)=0$. The following corollaries are apparently more general than the theorems, because they assume only that an interval $\left[t_{0}, t_{0}^{\prime}\right]$ is known such that $x(t)=0$ for some $t \in\left[t_{0}, t_{0}^{\prime}\right]$. This in essence requires that the inequalities hold for a wider class of functions $x(t)$, namely those for which $x(t)=0$ for some $t \in\left[t_{0}, t_{0}^{\prime}\right]$. We obtain the conditions of the corollaries as the intersection of conditions of the theorems over all points where it may be that $x(t)=0$.

CoRollary 3.5. Inequality (3.1) holds for all convex functions $\phi$ such that $\phi(0)=0$ and all increasing functions $x$ such that $x(t)=0$ for some $t \in\left[t_{0}, t_{0}^{\prime}\right], a \leqq t_{0} \leqq t_{0}^{\prime} \leqq b$, if and only if $0 \leqq G(t) \leqq 1, a \leqq$ $t<t_{0}^{\prime}$ and $0 \leqq \bar{G}(t) \leqq 1, t_{0} \leqq t \leqq b$.

COROLlary 3.6. Inequality (3.4) holds for all convex functions $\phi$ such that $\dot{\phi}(0)=0$ and all increasing functions $x$ such that $x(t)=0$ for some $t \in\left[t_{0}, t_{0}^{\prime}\right], a \leqq t_{0} \leqq t_{0}^{\prime} \leqq b$, if and only if either there exists $s \leqq t_{0}^{\prime}$ such that $G(t) \leqq 0, t<s, G(t) \geqq 1, s \leqq t<t_{0}^{\prime}$, and $\bar{G}(t) \leqq 0, t \geqq$ $t_{0}$, or there exists $s \geqq t_{0}$ such that $G(t) \leqq 0, t<t_{0}^{\prime}, G(t) \geqq 1, t_{0} \leqq t<s$ and $\bar{G}(t) \leqq 0, t \geqq s$.

The special cases of these corollaries in which $t_{0}=a, t_{0}^{\prime}=b$ are particularly interesting, though we do not explicitly spell them out. This case of Corollary 3.5 bears comparison with Theorem 1 of Brunk [5]. However, Brunk's conditions are of a different nature than ours, because they depend upon the function $x$.

Both Theorem 3.1a and Theorem 3.2a yield interesting corollaries when the condition $G(b)=1$ is imposed. In this case (3.3) reduces to (3.1) and (3.7) reduces to (3.4).

COROLlaRY 3.7. (3.1) holds for all convex functions $\phi$ and all increasing functions $x$ such that $x\left(t_{0}\right)=0$ if and only if (3.2) and $G(b)=1$.

COROLlary 3.8. (3.4) holds for all convex functions $\phi$ and all increasing functions $x$ such that $x\left(t_{0}\right)=0$ if and only if $G(b)=1$, and (3.5) or (3.6).

The sufficiency of these conditions follows from Theorems 3.1a and 3.2a. The necessity of $G(b)=1$ is obtained with $\phi(x) \equiv 1$ and $\phi(x) \equiv$ 
-1 in (3.1) and (3.4).

With $t_{0}=a$, the sufficiency of the conditions in Corollary 3.7 has been obtained by Brunk [5], Corollary 2 .

We point out that in both Theorems 3.1 and 3.2, the necessity of the conditions was proved using only nonnegative functions $\phi$. This means that the conditions for the inequalities to hold cannot be relaxed with the additional hypothesis that $\phi(x) \geqq 0$. It was with this fact in mind that we included Theorem 2.2, which is to be compared with Theorem 2.1.

Finally, we remark that results similar to those of this section can be obtained for functions $\phi$ concave-convex about the origin, $\phi(x) \leqq$ $(\geqq)-\phi(-x)$ for $x \geqq 0$ and $\phi(0)=0$. Discrete versions of such results have been obtained by Lawrence [11].

4. Inequalities for starshaped functions. We retain the convention of $\S 3$, that $-\infty \leqq a \leqq 0 \leqq b \leqq \infty$, and $G$ is a function of bounded variation on $[a, b]$ such that $G(u)=\int_{[a, u]} d G(x)$. Also, we continue to require $\int_{[a, b]} x(t) d G(t)<\infty$.

Theorem 4.1. Fix $t_{0} \in[a, b]$.

$$
\phi\left(\int_{[a, b]} x(t) d G(t)\right) \leqq \int_{[a, b]} \phi(x(t)) d G(t)
$$

for all supported starshaped functions $\phi$ such that $\phi(0)=0$ and all increasing functions $x$ such that $x\left(t_{0}\right)=0$ if and only if there exists $t_{1}$ and $t_{2}, a \leqq t_{1} \leqq t_{0} \leqq t_{2} \leqq b$, such that

$$
\begin{aligned}
& G(u)=0, u<t_{1} ; 0 \leqq G(u) \leqq 1 \text { and } G(u) \text { decreasing } \\
& \text { in } u, t_{1} \leqq u<t_{0}
\end{aligned}
$$

and

$$
\begin{aligned}
& 0 \leqq \bar{G}(u) \leqq 1 \text { and } \bar{G}(u) \text { increasing, } t_{0} \leqq u<t_{2} \\
& \bar{G}(u)=0, u \geqq t_{2} .
\end{aligned}
$$

Proof. Let $G^{*}(z)=G\{t: a \leqq t \leqq b$ and $x(t) \leqq z\}$, and let $H^{*}$ be degenerate at $m=\int_{-\infty}^{\infty} z d G^{*}(z)$. Then (4.1) can be rewritten as

$$
\int_{-\infty}^{\infty} \phi(z) d H^{*}(z) \leqq \int_{-\infty}^{\infty} \phi(z) d G^{*}(z)
$$

and the conditions (4.2), (4.3) can be rewritten as follows: There exist $z_{1}$ and $z_{2}, z_{1} \leqq 0 \leqq z_{2}$ such that 


$$
\begin{aligned}
& G^{*}(z)=0, z<z_{1} ; 0 \leqq G^{*}(z) \leqq 1 \text { and } G^{*}(z) \text { decreasing } \\
& \text { in } z, z_{1} \leqq z \leqq 0
\end{aligned}
$$

and

$$
\begin{aligned}
& 0 \leqq \bar{G}^{*}(z) \leqq 1 \text { and } \bar{G}^{*}(z) \text { increasing in } z, 0 \leqq z<z_{2} ; \\
& \bar{G}^{*}(z)=0, z \geqq z_{2} .
\end{aligned}
$$

We suppose that $\left(4.2^{\prime}\right)$ and $\left(4.3^{\prime}\right)$ hold, and verify the conditions of Theorem 2.6 with $\mu=G^{*}-H^{*}$.

By definition of $G^{*}$ and $H^{*}$, we have (2.7).

To check (2.5), we first note that

$$
m \equiv \int_{-\infty}^{\infty} x d G^{*}(x)=\int_{0}^{\infty} \bar{G}^{*}(x) d x-\int_{-\infty}^{0} G^{*}(x) d x=\int_{0}^{z_{2}} \bar{G}^{*}(x) d x-\int_{z_{1}}^{0} G^{*}(x) d x .
$$

Consequently

$$
z_{1} \leqq m \leqq z_{2}
$$

Further, we note that integration by parts yields

$$
\int_{(-\infty, u]} x d G^{*}(x)=u G^{*}(u)-\int_{(-\infty, u]} G^{*}(x) d x .
$$

To check (2.5), we must show that

$$
\int_{(-\infty, u]} x d G^{*}(x) \leqq \int_{(-\infty, u]} x d H^{*}(x), u \leqq 0 .
$$

(a) If $u<z_{1}$, then by (4.4), $u<m$ so that

$$
0=\int_{(-\infty, u]} x d G^{*}(x)=\int_{(-\infty, u]} x d H^{*}(x) .
$$

(b) If $z_{1}<u<m \leqq 0$,

$$
\begin{aligned}
& \int_{(-\infty, u]} x d G^{*}(x)-\int_{(-\infty, u]} x d H^{*}(x)=\int_{(-\infty, u]} x d G^{*}(x) \\
& =u G^{*}(u)-\int_{(-\infty, u]} G^{*}(x) d x \leqq u G^{*}(x) \leqq 0 \text { by }\left(4.2^{\prime}\right) .
\end{aligned}
$$

(c) If $z_{1}<m<u<0$,

$$
\begin{aligned}
\int_{(-\infty, u]} & x d G^{*}(x)-\int_{(-\infty, u]} x d H^{*}(x) \\
= & u G^{*}(u)-\int_{z_{1}}^{u} G^{*}(x) d x+\int_{z_{1}}^{0} G^{*}(x) d x-\int_{0}^{z_{2}} \bar{G}^{*}(x) d x \\
= & u G^{*}(u)+\int_{u}^{0} G^{*}(x) d x-\int_{0}^{z_{2}} \bar{G}^{*}(x) d x \\
& \leqq u G^{*}(u)+\int_{u}^{0} G^{*}(x) d x \leqq u G^{*}(u)+G^{*}(u) \int_{u}^{0} d x=0 .
\end{aligned}
$$


Next, we must check (2.6), i.e., $\int_{[u, \infty)} x d G^{*}(x) \geqq \int_{[u, \infty)} x d H^{*}(x), u \geqq 0$.

(a) If $0 \leqq u \leqq m \leqq z_{2}$, then

$$
\begin{aligned}
\int_{[u, \infty)} x d G^{*}(x)-\int_{[u, \infty)} x d H^{*}(x) \\
=u \bar{G}^{*}\left(u^{-}\right)+\int_{u}^{z_{2}} \bar{G}^{*}(x) d x-\int_{0}^{z_{2}} \bar{G}^{*}(x) d x+\int_{z_{1}}^{0} G^{*}(x) d x \\
\geqq u \bar{G}^{*}\left(u^{-}\right)-\int_{0}^{u} \bar{G}^{*}(x) d x \geqq u \bar{G}^{*}\left(u^{-}\right)-\bar{G}^{*}\left(u^{-}\right) \int_{0}^{u} d x=0 .
\end{aligned}
$$

(b) If $m<u<z_{2}$ and $u \geqq 0$,

$$
\begin{aligned}
& \int_{[u, \infty)} x d G^{*}(x)-\int_{[u, \infty)} x d H^{*}(x) \\
& \quad=\int_{[u, \infty)} x d G^{*}(x)=u \bar{G}^{*}\left(u^{-}\right)+\int_{u}^{z_{2}} \bar{G}^{*}(x) d x \geqq 0 .
\end{aligned}
$$

(c) If $u \geqq z_{2}$, then

$$
\int_{[u, \infty)} x d G^{*}(x)=\int_{[u, \infty)} x d H^{*}(x)=0 .
$$

This concludes the proof that (4.2) and (4.3) imply (4.1). It remains to show the converse.

Following the proof of Theorem 3.1, we conclude that $s_{2}>t_{0}$ implies $0 \leqq \bar{G}\left(s_{2}\right) \leqq 1$, and $s_{1}<t_{0}$ implies $0 \leqq G\left(s_{1}\right) \leqq 1$.

Next, suppose that $t_{0}<s_{2}<s_{2}+\delta$ and that $\bar{G}\left(s_{2}+\delta\right)>0$.

$$
\text { Let } x(t)=\left\{\begin{array}{ll}
0, & t \leqq s_{2} \\
1, & s_{2}<t \leqq s_{2}+\delta \\
1+\varepsilon, & t>s_{2}+\delta
\end{array} \text { and let } \phi(z)=\left\{\begin{array}{l}
0, z \leqq 1 \\
z, z>1
\end{array}\right.\right.
$$

Then for sufficiently large $\varepsilon$,

$$
\begin{aligned}
\int x(t) d G(t) & =\bar{G}\left(s_{2}\right)-\bar{G}\left(s_{2}+\delta\right)+(1+\varepsilon) \bar{G}\left(s_{2}+\delta\right) \\
& =\bar{G}\left(s_{2}\right)+\varepsilon \bar{G}\left(s_{2}+\delta\right)>1,
\end{aligned}
$$

and (4.1) becomes

$$
(1+\varepsilon) \bar{G}\left(s_{2}+\delta\right) \geqq \bar{G}\left(s_{2}\right)+\varepsilon \bar{G}\left(s_{2}+\delta\right),
$$

that is

$$
\bar{G}\left(s_{2}+\delta\right) \geqq \bar{G}\left(s_{2}\right) .
$$

This proves (4.3). Condition (4.2) follows similarly with 


$$
x(t)=\left\{\begin{array}{cl}
-(1+\varepsilon), & t \leqq s_{1} \\
-1, & s_{1}<t \leqq s_{1}+\delta \\
0, & t>s_{1}+\delta,
\end{array} \text { and } \phi(z)=\left\{\begin{array}{c}
-z, z<-1 \\
0, \quad z \geqq-1,
\end{array}\right.\right.
$$

where $s_{1}<s_{1}+\delta<t_{0}$.

TheOREM 4.2. Fix $t_{0} \in[a, b]$.

$$
\phi\left(\int_{[a, b]} x(t) d G(t)\right) \leqq \int_{[a, b]} \phi(x(t)) d G(t)
$$

for all starshaped functions $\phi$ such that $\phi(0)=0$ and all increasing functions $x$ such that $x\left(t_{0}\right)=0$ if and only if either

there exists $t_{1}, a \leqq t_{1} \leqq t_{0}$ such that $G(u)=0, u<t_{1}$;

$0 \leqq G(u) \leqq 1$ and $G(u)$ decreasing in $u, t_{1} \leqq u<t_{0}$, and $\bar{G}(u)=0, u \geqq t_{0}$,

or

there exists $t_{2}, t_{0} \leqq t_{2} \leqq b$, such that $G(u)=0, u<t_{0}$, $0 \leqq \bar{G}(u) \leqq 1$ and $\bar{G}(u)$ increasing, $t_{0}<u<t_{2}, \bar{G}(u)=$ $0, u \geqq t_{2}$.

Proof. Though (4.5) can be obtained from Theorem 2.5, we use Theorem 4.1. If (4.6) or (4.7), then (4.2) and (4.3) and in addition, $G$ has no mass to the right of $t_{0}$, or no mass to the left of $t_{0}$. Thus, the integrals of the inequality can be extended over $\left[a, t_{0}\right]$ (where $x(t) \leqq 0$ ) or over $\left[t_{0}, b\right]$ (where $x(t) \geqq 0$ ). But on $(-\infty, 0]$ or $[0, \infty)$, starshaped functions $\phi$ are supported starshaped functions and the inequality follows from Theorem 4.1.

$$
\text { Let } x(t)=\left\{\begin{array}{l}
-1, t \leqq t_{1} \\
0, t_{1}<t \leqq t_{2} \quad \text { where } t_{1}<t_{0}<t_{2}, \\
\alpha, t>t_{2}
\end{array}\right.
$$

and suppose $G\left(t_{1}\right)>0, \bar{G}\left(t_{2}\right)>0$. Then $m=\int_{a}^{b} x(t) d G(t)=\alpha \bar{G}\left(t_{2}\right)-G\left(t_{1}\right)$ is strictly positive for some $\alpha$ and strictly negative for some $\alpha$. According to Theorem 2.5, we must have $\int_{\left[a, t_{0}\right)} x(t) d \mu(t)=0$, where $\mu=G-H$ and $H$ is a probability distribution degenerate at $m$. This is impossible, since $m$ can be strictly positive or strictly negative while $\int_{\left[a, t_{0}\right)} x(t) d G(t)$ is unchanged.

THEOREM 4.3. Fix $t_{0} \in[a, b]$. 


$$
\phi\left(\int_{[a, b]} x(t) d G(t)\right) \geqq \int_{[a, b]} \phi(x(t)) d G(t)
$$

for all supported starshaped functions $\phi$ such that $\phi(0)=0$ and all increasing functions $x$ such that $x\left(t_{0}\right)=0$ if and only if either

there exists $t_{1}, a \leqq t_{1} \leqq t_{0}$, such that $G(t)=0$, $a \leqq t<t_{1} ; G(t) \geqq 1$ and $G(t)$ is increasing, $t_{1} \leqq t<t_{0} ; \bar{G}(t) \leqq 0, t_{0} \leqq t \leqq b$,

or

there exists $t_{2}, t_{0} \leqq t_{2} \leqq b$, such that $G(t) \leqq 0$, $a \leqq t<t_{0} ; \bar{G}(t) \geqq 1$ and $\bar{G}(t)$ is decreasing in $t, t_{0} \leqq t<t_{2} ; \bar{G}(t)=0, t_{2} \leqq t \leqq b$.

Proof. Let $H^{*}(z)=G\{t: a \leqq t \leqq b$ and $x(t) \leqq z\}$, and let $G^{*}$ be the probability distribution degenerate at $\int_{-\infty}^{\infty} z d H^{*}(z)$. Then $(4.8)$ can be rewritten as

$$
\int_{-\infty}^{\infty} \phi(z) d G^{*}(z) \geqq \int_{-\infty}^{\infty} \phi(z) d H^{*}(z)
$$

and (4.10) can be rewritten as

$$
\text { there exists } z_{2}>0 \text { such that } H^{*}(z) \leqq 0, z<0 \text {; }
$$

$$
\begin{aligned}
& \bar{H}^{*}(z) \geqq 1 \text { and } \bar{H}^{*}(z) \text { is decreasing in } z, 0 \leqq \\
& z<z_{2} ; \bar{H}^{*}(z)=0, z \geqq z_{2} .
\end{aligned}
$$

We show that $\left(4.10^{\prime}\right)$ implies $\left(4.8^{\prime}\right)$ by applying Theorem 2.6 with $\mu=G^{*}-H^{*}$. First, note that

$$
\begin{aligned}
m & =\int_{-\infty}^{\infty} z d H^{*}(z)=\int_{0}^{\infty} \bar{H}^{*}(z) d z \\
& -\int_{-\infty}^{0} H^{*}(z) d z \geqq \int_{0}^{z_{2}} \bar{H}^{*}(z) d z \geqq z_{2},
\end{aligned}
$$

since $\bar{H}^{*}(z) \geqq 0, z \geqq 0, \bar{H}^{*}(z) \geqq 1,0<z<z_{2}$, and $H^{*}(z) \leqq 0, z \leqq 0$.

Clearly (2.7) is satisfied. To verify (2.5), we note by (4.11) that $m \geqq 0$ so $(2.5)$ is $\int_{(-\infty, u]} z d H^{*}(z) \geqq 0, u \leqq 0$. But

$$
\int_{(-\infty, u]} z d H^{*}(z)=u H^{*}(u)-\int_{-\infty}^{u} H^{*}(z) d z \geqq 0
$$

because $H^{*}(z)<0, z \leqq u, H^{*}(u)<0$ and $u \leqq 0$.

To verify (2.6), suppose first that $u>z_{2}$. Then (2.6) becomes $\int x d G^{*}(x) \geqq 0$ which follows from (4.11). If $u \leqq z_{2}$ (then $u \leqq m$ by 
(4.11)), (2.6) becomes

$$
\int_{[u, \infty)} z d G^{*}(z) \geqq \int_{\left[u, z_{2}\right)} z d H^{*}(z), \quad \text { i.e., } \int_{-\infty}^{\infty} z d H^{*}(z) \geqq \int_{\left[u, z_{2}\right)} z d H^{*}(z),
$$

or

$$
\int_{(-\infty, 0]} z d H^{*}(z)+\int_{(0, u]} z d H^{*}(z) \geqq 0
$$

Now

$$
\int_{(-\infty, 0]} z d H^{*}(z)=-\int_{-\infty}^{0} H^{*}(z) d z \geqq 0
$$

and

$$
\int_{(0, u\rfloor} z d H^{*}(z)=-u \bar{H}^{*}(u)+\int_{0}^{u} \bar{H}^{*}(z) d z \geqq 0
$$

because $\bar{H}^{*}(z)$ is decreasing in $z, 0<z<z_{2}$.

The proof that (4.9) implies (4.8) is analogous. Consequently, we turn to the problem of showing that (4.9) or (4.10) is necessary. Suppose that (4.8) holds.

A. $\bar{G}\left(s_{2}\right) \geqq 1$ or $\bar{G}\left(s_{2}\right) \leqq 0, s_{2}>t_{0} ; G\left(s_{1}\right) \geqq 1$ or $G\left(s_{1}\right) \leqq 0, s_{1}<t_{0}$.

To see this, let $\phi(z)=z^{2}$; first let

$$
x(t)=\left\{\begin{array}{l}
0, t \leqq s_{2} \\
1, t>s_{2}
\end{array}, \text { then let } x(t)=\left\{\begin{array}{r}
-1, t \leqq s_{1} \\
0, t>s_{1}
\end{array} .\right.\right.
$$

Apply (4.8) to obtain $\left[\bar{G}\left(s_{2}\right)\right]^{2} \geqq \bar{G}\left(s_{2}\right)$ and $\left[G\left(s_{1}\right)\right]^{2} \geqq G\left(s_{1}\right)$.

B. $G\left(s_{1}\right) \bar{G}\left(s_{2}\right) \leqq 0$ if $s_{1}<t_{0}<s_{2}$.

To see this, suppose the contrary, let

$$
x(t)=\left\{\begin{array}{c}
-1 /\left|G\left(s_{1}\right)\right|, t \leqq s \\
0, s_{1}<\quad t \leqq s_{2} \\
1 /\left|\bar{G}\left(s_{2}\right)\right|, t>s_{2},
\end{array}\right.
$$

and let

$$
\dot{\phi}_{1}(z)=\left\{\begin{array}{l}
z, z \leqq 0 \\
0, z \geqq 0,
\end{array} \quad \dot{\phi}_{2}(z)=\left\{\begin{array}{l}
0, z \leqq 0 \\
z, z \geqq 0
\end{array}\right.\right.
$$

Then $\int_{[a, b]} x(t) d G(t)=0$. With $\phi \equiv \phi_{1}$, (4.8) becomes

$$
0 \geqq-G\left(s_{1}\right) /\left|G\left(s_{1}\right)\right|, \quad \text { a contradiction if } G\left(s_{1}\right)<0 \text {; }
$$

with $\phi \equiv \phi_{2}$, (4.8) becomes

$$
0 \geqq \bar{G}\left(s_{2}\right) /\left|\bar{G}\left(s_{2}\right)\right|, \quad \text { a contradiction if } \bar{G}\left(s_{2}\right)>0 \text {. }
$$


C. If $t_{0}<s_{2}<s_{2}+\delta \leqq b$ and $\bar{G}\left(s_{2}+\delta\right) \geqq 1$, then $\bar{G}\left(s_{2}\right) \geqq \bar{G}\left(s_{2}+\delta\right)$. To see this, suppose the contrary, that $\bar{G}\left(s_{2}\right)<\bar{G}\left(s_{2}+\delta\right)$.

$$
\text { Let } \quad x(t)=\left\{\begin{array}{ll}
0, & t \leqq s_{2} \\
1, & s_{2}<t \leqq s_{2}+\delta \\
1+\varepsilon, t>s_{2}+\delta
\end{array} \quad \phi(x)=\left\{\begin{array}{l}
0, x<1 \\
x, x \geqq 1 .
\end{array}\right.\right.
$$

Then

$$
\begin{aligned}
m & =\int_{a}^{b} x(t) d G(t)=\left[\bar{G}\left(s_{2}\right)-\bar{G}\left(s_{2}+\delta\right)\right]+(1+\varepsilon) \bar{G}\left(s_{2}+\delta\right) \\
& =\varepsilon \bar{G}\left(s_{2}+\delta\right)+\bar{G}\left(s_{2}\right),
\end{aligned}
$$

and $m<\bar{G}\left(S_{2}+\delta\right)$ for sufficiently small $\varepsilon>0$. From (4.8), we conclude that

$$
0 \geqq \int_{\left(s_{2}+\delta, b\right]} \phi(1+\varepsilon) d G(t)=(1+\varepsilon) \bar{G}\left(s_{2}+\delta\right)
$$

contradicting $\bar{G}\left(s_{2}+\delta\right) \geqq 1$.

$\mathrm{C}^{\prime}$. If $a \leqq s_{1}<s_{1}+\delta<t_{0}$, and $G\left(s_{1}\right) \geqq 1$, then $G\left(s_{1}+\delta\right) \geqq G\left(s_{1}\right)$. The proof of this is analogous to $C$ above.

D. If $t_{0}<s_{2}<s_{2}+\delta \leqq b, \bar{G}\left(s_{2}\right) \geqq 1$, and $\bar{G}\left(s_{2}+\delta\right) \leqq 0$, then $\bar{G}\left(s_{2}+\delta\right)=0$.

If we assume the contrary and take $x(t), \phi(x)$ as in $C$, we can choose $\varepsilon>0$ so that $0<m<1$. Then (4.8) becomes

$$
0 \geqq\left[\bar{G}\left(s_{2}\right)-\bar{G}\left(s_{2}+\delta\right)\right]+(1+\varepsilon) \bar{G}\left(t_{2}+\delta\right)=\bar{G}\left(s_{2}\right)+\varepsilon \bar{G}\left(s_{2}+\delta\right)=m,
$$

contradicting $m>0$.

$\mathrm{D}^{\prime}$. If $a \leqq s_{1}<s_{1}+\delta<t_{0}, G\left(s_{1}+\delta\right) \geqq 1$ and $\bar{G}\left(s_{1}\right) \leqq 0$, then $\bar{G}\left(s_{1}\right)=0$.

The proof is analogous to $D$.

Theorem 4.4. Fix $t_{0} \in[a, b]$.

$$
\phi\left(\int_{[a, b]} x(t) d G(t)\right) \geqq \int_{[a, b]} \phi(x(t)) d G(t)
$$

for all starshaped functions $\phi$ such that $\phi(0)$ and all increasing functions $x$ such that $x\left(t_{0}\right)=0$ if and only if either

there exists $t_{1} \leqq t_{0}$ such that $G(t)=0, t<t_{1} ; G(t) \geqq 1$ and $G(t)$ is increasing, $t_{1} \leqq t<t_{0} ; \bar{G}(t)=0, t \geqq t_{0}$,

or

there exists $t_{2} \geqq t_{0}$ such that $\bar{G}(t) \geqq 1$ and $\bar{G}(t)$ is decreasing in $t, t_{0} \leqq t<t_{2} ; \bar{G}(t)=0, t>t_{2} ; G(t)=0, t<t_{0}$. 
Proof. Since every supported starshaped function is starshaped, the conditions (4.9) or (4.10) are necessary for (4.13). Suppose that (4.10) holds. Then, in order to satisfy (2.5) of Theorem 2.5 we must in addition guarantee that $\int_{-\infty}^{0} x d H^{*}(x)=0$, because, by (4.11), $m \geqq 0$. But $\int_{-\infty}^{0} x d H^{*}(x)=-\int_{-\infty}^{0} H^{*}(x) d x=0$ together with $H^{*}(x) \leqq 0, x<0$, implies $H^{*}(x)=0, x<0$. Thus (4.14) or (4.15) is necessary; it is sufficient by Theorem 4.3 since, on $[0, \infty)$ or $(-\infty, 0]$, starshaped functions $\phi$ are supported starshaped functions. If (4.14) or (4.15), the interval $[a, b]$ is effectively replaced by $\left[a, t_{0}\right]$ or $\left[t_{0}, b\right]$.

Only minor modifications of Theorems 4.2 and 4.4 are required to eliminate the condition $\phi(0)=0$, provided that $x(t) \neq 0$ for $t \neq t_{0}$. In this case, the inequalities depend upon $\phi(0)$ only through $G\left\{t_{0}\right\}$. Since starshaped functions $\phi$ satisfy $\phi(0) \leqq 0$, conditions can be imposed on $G\left\{t_{0}\right\}$ so that the inequalities do not become false even when $-\dot{\phi}(0)$ is arbitrarily large. In the case of Theorem 4.2, the condition $G\left\{t_{0}\right\} \leqq 0$ must be added; in the case of Theorem 4.4, the condition $G\left\{t_{0}\right\} \geqq 0$ is required.

The most natural domain for starshaped functions is $[0, b]$; on this domain, a starshaped function is a supported starshaped function. From Theorem 4.1 or 4.2 we obtain the special case of

COROLlaRY 4.5 .

$$
\dot{\phi}\left(\int_{[0, b]} x(t) d G(t)\right) \leqq \int_{[0, b]} \phi(x(t)) d G(t)
$$

for all starshaped functions $\phi$ such that $\phi(0)=0$ and all increasing functions $x$ such that $x(0)=0$ if and only if there exists $t_{2}, 0 \leqq t_{2} \leqq b$, such that $0 \leqq \bar{G}(u) \leqq 1$ and $\bar{G}(u)$ is increasing, $0 \leqq u<t_{2}$, and $\bar{G}(u)=$ $0, u \geqq t_{2}$.

Similarly from Theorem 4.3 or 4.4 we obtain

COROLlary 4.6 .

$$
\phi\left(\int_{[0, b]} x(t) d G(t)\right) \geqq \int_{[\mathrm{r}, b]} \phi(x(t)) d G(t)
$$

for all starshaped functions $\phi$ such that $\phi(0)=0$ and all increasing functions $x$ such that $x(0)=0$ if and only if there exists $t_{2}, 0 \leqq t_{2} \leqq b$, such that $\bar{G}(t) \geqq 1$ and $\bar{G}(t)$ is decreasing in $t, 0 \leqq t<t_{2} ; \bar{G}(t)=0$, $t_{-} \geqq t_{2}$.

In the same spirit as Corollaries 3.5 and 3.6, and via the same 
argunments, we obtain from Theorems 4.1 and 4.3 the following corollaries:

COROLLARY 4.7. (4.1) holds for all supported starshaped functions $\phi$ and all increasing functions $x$ such that $x(t)=0$ for some $t \in\left[t_{0}, t_{0}^{\prime}\right]$, $a \leqq t_{0} \leqq t_{0}^{\prime} \leqq b$, if and only if there exists $t_{1}$ and $t_{2}, t_{1} \leqq t_{2}, a \leqq t_{1} \leqq t_{0}^{\prime}$, $t_{0} \leqq t_{2} \leqq b$, such that $G(u)=0, a \leqq u<t_{1} ; 0 \leqq G(u) \leqq 1$ and $G(u)$ decreasing in $u, t_{1} \leqq u<t_{0}^{\prime} ; 0 \leqq \bar{G}(u) \leqq 1$ and $\overline{\bar{G}}(u)$ increasing, $t_{0} \leqq u<$ $t_{2} ; \bar{G}(u)=0, t_{2} \leqq u \leqq b$.

COROLLARY 4.8. (4.8) holds for all supported starshaped functions and all increasing functions $x$ such that $x(t)=0$ for some $t \in\left[t_{0}, t_{0}^{\prime}\right]$, $a \leqq t_{0} \leqq t_{0}^{\prime} \leqq b$ if and only if either (i) there exists $t_{1}, a \leqq t_{1} \leqq t_{0}^{\prime}$, such that $G(t)=0, a \leqq t<t_{1} ; G(t) \geqq 1$ and $G(t)$ increasing, $t_{1} \leqq t<t_{0}^{\prime}$; $\bar{G}(t) \leqq 0, t_{0} \leqq t \leqq b$, or (ii) there exists $t_{2}, t_{0} \leqq t_{2} \leqq b$, such that $\bar{G}(t) \geqq 1$ and $\bar{G}(t)$ is decreasing, $t_{0} \leqq t<t_{2} ; \bar{G}(t)=0, t_{2} \leqq t \leqq b ; G(t) \leqq 0, a \leqq$ $t<t_{0}^{\prime}$, or (iii) $G$ is a point mass of at least one at some point $s \in\left[t_{0}, t_{0}^{\prime}\right]$.

We remark that (i) guarantees that (4.9) holds and (ii) guarantees (4.10) holds no matter what $t \in\left[t_{0}, t_{0}^{\prime}\right]$ satisfies $x(t)=0$. However (iii) guarantees (4.9) when $t>s$ and (4.10) when $t<s$.

Again, the special cases $t_{0}=a, t_{0}^{\prime}=b$ are of particular interest, and may be easily written out. This case of Corollary 4.8 takes a particularly simple form because only (iii) is possible.

5. Discrete versions. Some results similar to those of $\S 3$ are known in the discrete case. One such inequality is due to Szëgo [14]; it states that if $0<x_{1} \leqq x_{2} \leqq \cdots \leqq x_{2 m-1}$ and $\phi$ is convex on $\left[0, x_{2 m-1}\right]$, then

$$
\phi\left[\sum_{j=1}^{2 m-1}(-1)^{j-1} x_{j}\right] \leqq \sum_{j=1}^{2 m-1}(-1)^{j-1} \phi\left(x_{j}\right) .
$$

Closely related results were obtained by Weinberger [15], Bellman [3], and Wright [16]. These results were further generalized by Brunk [5] and Olkin [13], who proved that if $0 \leqq b_{1} \leqq \cdots \leqq b_{n} \leqq 1$, if $0 \leqq$ $x_{1} \leqq \cdots \leqq x_{n}$, and if $\phi$ is convex, then

$$
\phi\left[\sum_{j=1}^{n}(-1)^{n-j} b_{j} x_{j}\right]-\phi(0) \leqq \sum_{j=1}^{n}(-1)^{n-j} b_{j}\left[\phi\left(x_{j}\right)-\phi(0)\right] \text {. }
$$

Notice that if $n=2 m-1$ and $b_{j} \equiv 1$, then (5.2) reduces to (5.1).

Theorem 3.1a yields necessary and sufficient conditions on $a_{1}, a_{2}, \cdots$, $a_{n}$ in order that

$$
\phi\left(\sum_{j=1}^{n} a_{j} x_{j}\right)-\phi(0) \leqq \sum_{j=1}^{n} a_{j}\left[\phi\left(x_{j}\right)-\phi(0)\right]
$$


for all convex functions $\phi$ and $0 \leqq x_{1} \leqq \cdots \leqq x_{n}$. In addition, discrete versions of various other results are of interest.

In the following, we assume that $\phi(0)=0$, so that (5.3) becomes

$$
\phi\left(\sum_{j=1}^{n} a_{j} x_{j}\right) \leqq \sum_{j=1}^{n} a_{j} \phi\left(x_{j}\right) .
$$

For various conditions on the $x_{j}$, below are listed necessary and sufficient conditions on the $a_{j}$ in order that (5.4) holds for all convex functions $\phi$ such that $\phi(0)=0$. Similarly, conditions are listed for its reversal,

$$
\phi\left(\sum_{1}^{n} a_{j} x_{j}\right) \geqq \sum_{1}^{n} a_{j} \dot{\phi}\left(x_{j}\right) .
$$

We use the notation $A_{i}=\sum_{1}^{i} a_{j}$ and $\bar{A}_{i}=\sum_{i}^{n} \alpha_{j}$.

A. $0 \leqq x_{1} \leqq \cdots \leqq x_{n}$ :

(5.4) if and only if $0 \leqq \bar{A}_{i} \leqq 1,1 \leqq i \leqq n$;

(5.5) if and only if there exists $j, 0 \leqq j \leqq n$ such that $\bar{A}_{i} \geqq 1$, $1 \leqq i \leqq j, \bar{A}_{i} \leqq 0, j+1 \leqq i \leqq n$.

B. $x_{1} \leqq \cdots \leqq x_{n}$ :

(5.4) if and only if $0 \leqq A_{i} \leqq 1$ and $0 \leqq \bar{A}_{i} \leqq 1,1 \leqq i \leqq n$;

(5.5) if and only if $A_{i} \leqq 0$ and $\bar{A}_{i} \leqq 0, i=1,2, \cdots, n$, or for some $j, 0 \leqq j \leqq n, \bar{A}_{1} \geqq 1, \cdots, \bar{A}_{j} \geqq 1, \bar{A}_{j+1} \leqq 0, \cdots, \bar{A}_{n} \leqq$ 0 , and $\bar{A}_{i} \geqq \bar{A}_{1}, 1 \leqq i \leqq j$. Note that this last condition is equivalent to $A_{1} \leqq 0, \cdots, A_{k-1} \leqq 0, A_{k+1} \geqq 1, \cdots, A_{n} \geqq$ 1 , and $A_{i} \geqq A_{k}, k \leqq i \leqq n$, for some $k,(1 \leqq k \leqq n)$.

C. $x_{1} \leqq \cdots \leqq x_{k} \leqq 0 \leqq x_{k+1} \leqq \cdots \leqq x_{n}$ :

(5.4) if and only if $0 \leqq A_{i} \leqq 1,1 \leqq i \leqq k$, and $0 \leqq \bar{A}_{i} \leqq 1$, $k+1 \leqq i \leqq n$;

(5.5) if and only if there exists $j \leqq k$ such that $A_{i} \leqq 0, i<j$; $A_{i} \geqq 1, j \leqq i \leqq k ; \bar{A}_{i} \leqq 0, i \geqq k+1$, or there exists $j \geqq$ $k$ such that $A_{i} \leqq 0, i \leqq k ; \bar{A}_{i} \geqq 1, k+1 \leqq i \leqq j ; \bar{A}_{i} \leqq$ $0, i>j$.

D. $x_{1} \leqq \cdots \leqq x_{n}$ and $x_{k} \leqq 0 \leqq x_{l}(k \leqq l)$ :

(5.4) if and only if $0 \leqq A_{i} \leqq 1, i<l$, and $0 \leqq \bar{A}_{i} \leqq 1, i>k$;

(5.5) if and only if there exists $1 \leqq j \leqq l$ such that $A_{i} \leqq 0$, $i<j ; A_{i} \geqq 1, j \leqq i<l ; \bar{A}_{i} \leqq 0, i \geqq k+1$, or there exists $k \leqq j \leqq n$ such that $A_{i} \leqq 0, i<l, \bar{A}_{i} \geqq 1, k+1 \leqq$ $i \leqq j ; \bar{A}_{i} \leqq 0, i>j$.

We turn now to the case that $\phi$ is a supported starshaped function such that $\phi(0)=0$; below are necessary and sufficient conditions for (5.4) and for (5.5) to hold for all such functions with various conditions on the $x_{i}$.

A. $0 \leqq x_{1} \leqq \cdots \leqq x_{n}$ :

(5.4) if and only if for some $j, 0 \leqq j \leqq n, 0 \leqq \bar{A}_{1} \leqq \bar{A}_{2} \leqq \cdots \leqq$ 


$$
\bar{A}_{j} ; \bar{A}_{j+1}=\cdots=\bar{A}_{n}=0 .
$$

(5.5) if and only if for some $j, 0 \leqq j \leqq n, \bar{A}_{1} \geqq \bar{A}_{2} \geqq \cdots \geqq$ $\bar{A}_{j} \geqq 1, \bar{A}_{j+1}=\cdots=\bar{A}_{n}=0$.

B. $x_{1} \leqq \cdots \leqq x_{n}$ :

(5.4) if and only if for some $j, 0 \leqq j \leqq n, 0 \leqq a_{j} \leqq 1$ and $a_{i}=$ $0, i \neq j$.

(5.5) if and only if for some $j, 0 \leqq j \leqq n, a_{j} \geqq 1$ and $a_{i}=0$, $i \neq j$. This condition arises from (iii) of Theorem 4.8. C. $x_{1} \leqq \cdots \leqq x_{k} \leqq 0 \leqq x_{k+1} \leqq \cdots \leqq x_{n}$ :

(5.4) if and only if there exists $j_{1}$ and $j_{2}, j_{1} \leqq j_{2}, 1 \leqq j_{1} \leqq$ $k+1, k \leqq j_{2} \leqq n$, such that $A_{1}=\cdots=A_{j_{1-1}}=0,1 \geqq$ $A_{j_{1}} \geqq \cdots \geqq A_{k} \geqq 0,0 \leqq \bar{A}_{k+1} \leqq \cdots \leqq \bar{A}_{j_{2}} \leqq 1, \bar{A}_{j_{2}+1}=\cdots$ $=\bar{A}_{n}=0$.

(5.5) if and only if either

(i) there exists $j_{1}, 1 \leqq j_{1} \leqq k+1$ such that

$$
A_{1}=\cdots=A_{j_{1}-1}=0,1 \leqq A_{j_{1}} \leqq \cdots \leqq A_{k}, \bar{A}_{k+1}=\cdots=\bar{A}_{n}=0 \text {, }
$$

or

(ii) there exists $j_{2}, k \leqq j_{2} \leqq n$ such that

$$
A_{i} \leqq 0,1 \leqq i \leqq k, \bar{A}_{k+1} \geqq \cdots \geqq \bar{A}_{j_{2}} \geqq 1, \bar{A}_{j_{2}+1}=\cdots=\bar{A}_{n}=0,
$$

or

(iii) $a_{j} \geqq 1$ for $j=k$ or $k+1$ and $a_{i}=0, i \neq j$.

D. $x_{1} \leqq \cdots \leqq x_{n}$ and $x_{k} \leqq 0 \leqq x_{l}(k \leqq l)$ :

(5.4) if and only if there exists $j_{1} \leqq j_{2}, 1 \leqq j_{1} \leqq l, k \leqq j_{2} \leqq n$, such that $A_{1}=\cdots=A_{j_{1-1}}=0,1 \geqq A_{j_{1}} \geqq \cdots \geqq A_{l-1} \geqq$ $0,0 \leqq \bar{A}_{k+1} \leqq \cdots \leqq \bar{A}_{j_{2}} \leqq 1, \bar{A}_{j_{2}+1}=\cdots=\bar{A}_{n}=0$.

(5.5) if and only if either

(i) there exists $j_{1}, 1 \leqq j_{1} \leqq l$, such that

$A_{1}=\cdots=A_{j_{1}-1}=0,1 \leqq A_{j_{1}} \leqq \cdots \leqq A_{l-1}, \bar{A}_{k+1}=\cdots=\bar{A}_{n} \leqq 0$,

or

(ii) there exists $j_{2}, k \leqq j_{2} \leqq n$, such that

$A_{i} \leqq 0,1 \leqq i<l, \bar{A}_{k+1} \geqq \cdots \geqq \bar{A}_{j_{2}} \geqq 1, \bar{A}_{j_{2}+1}=\cdots=\bar{A}_{n}=0$,

or

(iii) there exists $j, k \leqq j \leqq l$, such that $a_{j} \geqq 1$ and $a_{i}=0, i \neq j$.

6. Applications. Our interest in the foregoing results arose from the study of statistical problems for certain restricted families of probability distributions of importance in reliability theory. We say that a distribution $F$ is convex (starshaped) with respect to $H$ if $F(0)=H(0)=0$ and $H^{-1} F$ is convex (starshaped) on the support of 
$F$. Of particular interest is the case that $H$ is the exponential distribution, i.e., $\bar{H}(x)=e^{-x}$ (other cases are interesting, e.g., $H(x)=x$, $0 \leqq x \leqq 1$ ).

Distributions $F$ convex with respect to the exponential distribution are called increasing hazard rate (IHR) distributions, because those that are absolutely continuous are characterized by having an increasing hazard rate $r(x)=[d F(x) / d x] / \bar{F}(x)$. Distributions $F$ starshaped with respect to the exponential distribution are called increasing hazard rate average (IHRA) distributions, because those that are absolutely continuous are characterized by the property that $(1 / t) \int_{0}^{t} r(x) d x$ is increasing. The properties of IHR and IHRA arise in formulating descriptions of "wearout" in reliability theory.

If $0 \leqq X_{1} \leqq \cdots \leqq X_{n}$ are order statistics from $F$, then $H^{-1} F\left(X_{i}\right)$ are distributed as order statistics $Y_{i}$ from $H$. With $\phi(x)=H^{-1} F(x)$, where $\phi$ is convex or starshaped, we obtain from the foregoing inequalities necessary and sufficient conditions on the $a_{i}$ in order that

$$
F\left(\sum a_{i} X_{i}\right) \stackrel{s t}{\leqq} H\left(\sum a_{i} Y_{i}\right) \quad \text { or } \quad H\left(\sum a_{i} Y_{i}\right) \stackrel{s t}{\leqq} F\left(\sum a_{i} X_{i}\right)
$$

where $\stackrel{s t}{\leqq}$ denotes "stochastically less than." Such inequalities are used by. Barlow and Proschan [2] to construct conservative tolerance limits for IHR or IHRA distributions.

\section{BIBLIOGRAPHY}

1. R. E. Barlow and F. Proschan, Inequalities for linear combinations of order statistics from restricted families, Ann. Math. Statist. 37 (1966), 1574-1592.

2. R. E. Barlow and F. Proschan, Tolerance and con fidence limits for classes of distributions based on failure rate, Ann. Math. Statist. 37 (1966), 1593-1601.

3. R. Bellman, On an inequality of Weinberger, Amer. Math. Monthly 60 (1953), 402.

4. A. M. Bruckner and E. Ostrow, Some function classes related to the class of convex functions, Pacific J. Math. 12 (1962), 1203-1215.

5. H. D. Brunk, On an inequality for convex funnctions, Proc. Amer. Math. Soc. 7 (1956), 817-824.

6. - Integral inequalities for functions with nondecreasing increments, Pacific J. Math. 14 (1964), 783-793.

7. G. H. Hardy, J. E. Littlewood and G. Pólya, Some simple inequalities satisfied by convex functions, Messenger of Math. 58 (1929), 145-152.

8. J. Karamata, Sur une inégalité relative aux functions convexes, Publ. Math. L'Uuiversité de Belgrade 1 (1932), 145-148.

9. S. Karlin and A. Novikoff Generalizei convex inequalities, Pacific J. Math. 13 (1963), 1251-1279.

10. S. Karlin, and W. Studden, Tchebycheff systems: With applications in analysis and Statistics, Interscience Publishers, New York, 1966.

11. M. J. Lawrence, Inequalities and tolerance limits for s-ordered distributions, Operations Research Center Report, ORC 66-37, University of California, Berkeley, 1966.

12. V. I. Levin and S. B. Stečkin, Inequalities, Amer. Math. Soc. Transl. (2) 14 (1948). $1-29$.

13. I. Olkin, On inequalities of Szegö and Bellman, Proc. Nat. Acad. Sci. U.S.A. 45 
(1959), 230-231.

14. G. Szegö, Über eine Verallgemeinerung des Dirichletschen Integrals, Math. Z. 52 (1950), 676-685.

15. H. F. Weinberger, An inequality with alternating signs, Proc. Nat. Acad. Sci. U.S.A. 38 (1952), 611-613.

16. E. M. Wright, An inequality for convex functions, Amer. Math. Monthly 61 (1954), 620-622.

17. Z. Ziegler, Generalized convexity cones, Pacific J. Math. 17 (1966), 561-580.

Received September 8, 1967.

UNIVERSITY OF CALIFORNIA, BERKELEY, AND

BOEING SCIENTIFIC RESEARCH LABORATORIES 



\section{Pacific Journal of Mathematics \\ Vol. 29, No. 1 \\ May, 1969}

Jorge Alvarez de Araya, A Radon-Nikodým theorem for vector and operator

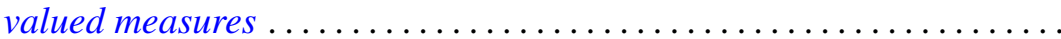

Deane Eugene Arganbright, The power-commutator structure of finite

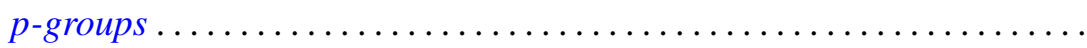

Richard Eugene Barlow, Albert W. Marshall and Frank Proschan, Some

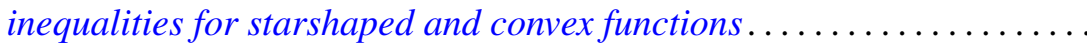

David Clarence Barnes, Some isoperimetric inequalities for the eigenvalues

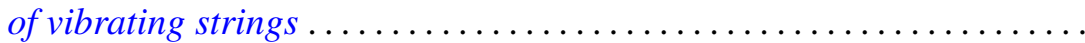

David Hilding Carlson, Critical points on rim-compact spaces ...........

Allan Matlock Weber Carstens, The lattice of pretopologies on an arbitrary

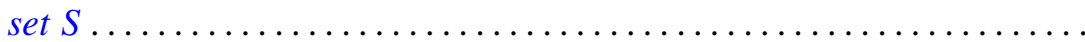

S. K. Chatterjea, A bilateral generating function for the ultraspherical

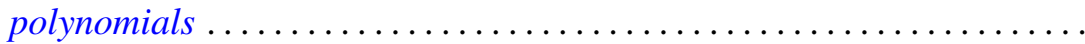

Ronald J. Ensey, Primary Abelian groups modulo finite groups ......... 77

Harley M. Flanders, Relations on minimal hypersurfaces ............ 83

Allen Roy Freedman, On asymptotic density in n-dimensions........... 95

Kent Ralph Fuller, On indecomposable injectives over artinian rings...... 115

George Isaac Glauberman, Normalizers of p-subgroups in finite groups . . . 137

William James Heinzer, On Krull overrings of an affine ring ........... 145

John McCormick Irwin and Takashi Ito, A quasi-decomposable abelian group without proper isomorphic quotient groups and proper isomorphic subgroups.

Allan Morton Krall, Boundary value problems with interior point boundary conditions

John S. Lowndes, Triple series equations involving Laguerre

polynomials

Philip Olin, Indefinability in the arithmetic isolic integers

Ki-Choul Oum, Bounds for the number of deficient values of entire functions whose zeros have angular densities..

R. D. Schafer, Standard algebras ....................

Wolfgang M. Schmidt, Irregularities of distribution. III.

Richard Alfred Tapia, An application of a Newton-like method to the Euler-Lagrange equation 